\title{
How Different Natural Energy Sources Affect the Shallow Geothermal Suitability in Urban Areas: The South Africa Case Study ${ }^{\dagger}$
}

\author{
Eloisa Di Sipio ${ }^{1, *}$, Antonio Galgaro ${ }^{1}$, Michele De Carli ${ }^{2}$, Paolo Greggio ${ }^{1}$, Mauro Mantovan ${ }^{3}$ \\ and Myron Sukha ${ }^{4}$ \\ 1 Department of Geosciences, University of Padova, 35131 Padova, Italy; antonio.galgaro@unipd.it (A.G.); \\ p_greggio@yahoo.it (P.G.) \\ 2 Department of Industrial Engineering, University of Padova, 35131 Padova, Italy; michele.decarli@unipd.it \\ 3 Hiref S.p.a, Tribano (Padova), 35020 Tribano (Padova), Italy; mauro.mantovan@hiref.it \\ 4 Hiref SA, Alrode South 1451 Alberton, South Africa; myron@hiref.co.za \\ * Correspondence: eloisa.disipio@unipd.it \\ † Presented at TERRAenVISION 2019, Barcelona, Spain, 2-7 September, 2019.
}

Published: 21 November 2019

\begin{abstract}
In recent years, the overall worldwide demand for energy has been increasing due to the constant growth of both global population and industrialization, which is particularly intensifying in emerging countries (China, India, South Africa, Brazil) and recently industrialized ones (i.e., Mexico, Turkey). In this framework, the exploitation of shallow geothermal energy through heat geo-exchange systems, as borehole heat exchangers (closed loop systems) or groundwater systems (open loop systems) coupled with a heat pump (Ground Source Heat Pump-GSHP), is really appealing, due to its versatility and energy efficiency. The heat exchanged with the underground, a reliable and green thermal energy source, is used mainly for heating and cooling of residential, industrial or commercial buildings and greenhouses. Several technologies are available and combinations with other local renewable energy sources are also possible, representing very interesting efficient and environmentally friendly solutions to be adopted in urban areas. The integration of different natural energy sources brings significant advantages, such as the reduction of $\mathrm{CO}_{2}$ emissions, the mitigation of the subsurface urban heat island effect, the minimization of electricity consumption. However, the underground suitability to low enthalpy geothermal systems is strictly related to the climatic, geological, hydrogeological, geothermal and thermophysical properties, typical of the area under investigation. The evaluation of these parameters allows to assess the amount of heat at disposal and the possibility to exchange it. On one hand, it is necessary to select and collect the data related to the factors that better characterize the ground behavior from the point of view of the heat exchange capacity. On the other, it is essential to integrate them in thematic maps created by Geographic Information System (GIS) tools, providing a preliminary evaluation of the territory suitability to geo-exchange and supporting the land use geothermal management both for closed and open loop systems. A preliminary representation of low-enthalpy geothermal resources suitability maps for Johannesburg, Durban and Cape Town, the three main urbanized cities of South Africa, representing the geological and climatic national variability of the country, is here presented. From a methodological point of view, these maps are created by assigning to each value of the descriptive parameters selected (i.e., lithology, type of aquifer, thermal conductivity, average annual air and ground temperature) a corresponding quantitative value, assessing its different attitude for thermal purposes. In this way, one of the first contribution to the suitability of geothermal energy resources in South Africa is obtained.
\end{abstract}


Keywords: shallow geothermal energy; geology; hydrogeology; urban area; South Africa

(C) 2019 by the authors. Licensee MDPI, Basel, Switzerland. This article is an open access article distributed under the terms and conditions of the Creative Commons Attribution (CC BY) license (http://creativecommons.org/licenses/by/4.0/). 